\title{
Effectiveness of audiovisual distraction eyewear and computerized delivery of anesthesia during pulp therapy of primary molars in phobic child patients
}

\author{
Kausar Sadia Fakhruddin ${ }^{1}$, El Batawi Hisham¹, Mehmet Omer Gorduysus ${ }^{1,2}$
}

Correspondence: Dr. Kausar Sadia Fakhruddin

Email: kfakhruddin@sharjah.ac.ae
${ }^{1}$ College of Dental Medicine, University of Sharjah, Sharjah, United Arab Emirates,

${ }^{2}$ Department of Endodontics, Hacettepe University, Faculty of Dentistry, Turkiye

\section{ABSTRACT}

Objectives: The aim of this study is to assess the effectiveness of audiovisual distraction technique with video eyewear and computerized delivery system-intrasulcular (CDS-IS) during the application of local anesthetic in phobic pediatric patients undergoing pulp therapy of primary molars. Materials and Methods: This randomized, crossover clinical study includes 60 children, aged between 4 and 7-year-old (31 boys and 29 girls). Children were randomly distributed equally into two groups as A and B. This study involved two treatment sessions of pulp therapy, 1-week apart. During treatment session I, group A had an audiovisual distraction with video eyewear, whereas group B had audiovisual distraction using projector display only without video eyewear. During treatment session II, group A had undergone pulp therapy without video eyewear distraction, whereas group B had the pulp treatment using video eyewear distraction. Each session involved the pulp therapy of equivalent teeth in the opposite sides of the mouth. At each visit scores on the Modified Child Dental Anxiety Scale (MCDAS) (f) were used to evaluate the level of anxiety before treatment. After the procedure, children were instructed to rate their pain during treatment on the Wong Bakers' faces pain scale. Changes in pulse oximeter and heart rate were recorded in every $10 \mathrm{~min}$. Results: From preoperative treatment session I (with video eyewear) to preoperative treatment session II (without video eyewear) for the MCDAS (f), a significant $(P>0.03)$ change in the mean anxiety score was observed for group A. Self-reported mean pain score decreases dramatically after treatment sessions' with video eyewear for both groups. Conclusion: The use of audiovisual distraction with video eyewear and the use of CDS-IS system for anesthetic delivery was demonstrated to be effective in improving children's cooperation, than routine psychological interventions and is, therefore, highly recommended as an effective behavior management technique for long invasive procedures of pulp therapy in young children.

Key words: Audiovisual distraction eyewear, dental anxiety, pulp therapy

\section{INTRODUCTION}

Several research studies support the proposition that pain or fear of pain is a primary source of dental anxiety and a major obstacle for seeking dental care. ${ }^{[1,2]}$ There are children who just cannot cope with the stimuli and behavioral demands associated with dental experience. Such fear ranges from fear of needle to fear of bodily harm to a general fear of the unknown. ${ }^{[3]}$ To assist in the management of a child with anxiety, a wide range of pharmacological and nonpharmacological methods are available to dentists. ${ }^{[4,5]}$
Recent dental studies ${ }^{[6-10]}$ have shown that distraction is a common technique used to reduce the pain

This is an open access article distributed under the terms of the Creative Commons Attribution-NonCommercial-ShareAlike 3.0 License, which allows others to remix, tweak, and build upon the work non-commercially, as long as the author is credited and the new creations are licensed under the identical terms.

For reprints contact: reprints@medknow.com

How to cite this article: Fakhruddin KS, El Batawi H, Gorduysus MO. Effectiveness of audiovisual distraction eyewear and computerized delivery of anesthesia during pulp therapy of primary molars in phobic child patients. Eur J Dent 2015;9:470-5.

DOI: $10.4103 / 1305-7456.172637$ 
reaction during short invasive procedures. Distraction techniques such as television watching, use of virtual reality, audiovisual eyeglasses, and listening to music may effectively help to distract the child's attention away from anxiety-provoking stimuli, leading to a relaxing experience for the child.

During the administration of a local anesthetic injection, an anxious patient might perceive more pain of longer duration as compared to less anxious patients. ${ }^{[6]}$ Some studies ${ }^{[11,12]}$ documented that computerized delivery system (CDS) for local anesthesia caused low levels of stress and pain reaction. The CDS works with a microprocessor which permits controlled low-pressure delivery of the anesthetic solution. Therefore, the pain perception during the computerized administration of a palatal injection was significantly lower, resulting in less disruptive behavior in pediatric patients.

The current study aims to compare the effectiveness of audiovisual distraction techniques (audiovisual using projector only and audiovisual with video eyewear) along with computerized delivery of anesthesia during the pulp therapy of primary molars in phobic child patients to reduce the child dental anxiety.

\section{MATERIALS AND METHODS}

This randomized, crossover clinical study was conducted at University Dental Hospital Sharjah, on approval obtained from Research Ethics Committee, University of Sharjah, United Arab Emirates.

The study included 60 children aged 4-7-year-old (31 boys and 29 girls). Scores on the faces version of the Modified Child Dental Anxiety Scale (MCDAS) (f $)^{[13]}$ were used to evaluate the level of anxiety in children before pulpectomy procedures carried out on primary molars. Treatment was planned as two appointments (or sessions). Both treatment sessions were 1-week apart. For the purpose of the current study, a score above 19 was considered as the high level of dental anxiety. As per inclusion criteria, children with previous dental experience and with MCDAS (f) score of 31 and above, with no systemic health issues that prevent them from undergoing endodontic treatment were recruited. An exclusion criterion includes patients with any visual or auditory deficits.

Children were randomly distributed equally into two groups as A and B using the stratified random selection method. Appointments were scheduled to ensure adequate time to perform all required treatment procedure and data collection. After reviewing medical history and radiographs, the patients in group A were seated and then video eyewear (Vuzix Wrap 310XL; Vuzix Corporation, Rochester, NY, USA), was placed on the patients' eyes and attached to the iPad and their preselected $60 \mathrm{~min}$ movie was played. The movies were age appropriate. The children were given the option to select their choice of the movie from the collection of Shaun the Sheep, Tinker Bell, Cars, and Smurfs series. The video eyewear blocked the visual field of the child completely and had headphones to deliver the sound. Following that blood oxygen saturation and pulse rate were monitored and recorded throughout the procedure every 10 min using a pulse oximeter. All the treatment procedure was carried out by one pediatric dentist. Patients were then anesthetized by CDS using "single tooth anesthesia machine." Root canal procedure started after rubber dam isolation. While deroofing the pulp chamber, few drops of local anesthetic using were delivered intrapulpally when needed.

After completion of questionnaire MCDAS (f), children assigned in group A, had first session of endodontic treatment (pulpectomy) using audiovisual distractor (AVD) video eyewear; whereas group B had undergone same treatment while watching movie of their choice projected through a projector on the ceiling above the dental chair without video eyewear. During session II, children in group A, had pulpectomy done on another tooth in different quadrant with AVD without eyewear, but children in group B wore video eyewear while watching cartoon movie of their preference while undergoing pulp therapy.

At the completion of the endodontic procedure, pulse oximeter and AVD glasses were removed and the patients' were instructed to rate their pain during treatment procedure on the Wong Bakers' faces pain scale. ${ }^{[14]}$

After 1-week, another dental appointment was scheduled. The children were requested to fill out the one more time MCDAS (f) questionnaire before endodontic treatment scheduled for another tooth, with provision of AVD glasses for group B. A preselected 60 min movie was displayed on the ceiling above the dental chair using projector for group A, but without video eyewear. Blood oxygen saturation and pulse rate were monitored and recorded throughout the procedure every $10 \mathrm{~min}$ using pulse oximeter for approximately $45 \mathrm{~min}$ of pulpectomy procedure. 
At the completion of the procedure, pulse oximeter was removed and the patients' were instructed to rate their anxiety during the treatment procedure on the Wong Bakers' faces pain scale one more time. A paired sample $t$-test and independent sample $t$-test were used to assess the significance of changes during each visit. The statistical significance was set at 0.05 .

\section{RESULTS}

There was a random distribution of $n=60$ subjects into one of two groups, of 30 subject each [Figure 1]. Both the treatment groups had undergone pulp therapy treatment during the session I and II. Subjects assigned in treatment group A, use video eyewear to watch a movie during the session I, but during the treatment session II, the same group watched a movie without using video eyewear. Participants in group B, were not allowed to use video eyewear, during the session I, but during the treatment session II, the same group watched a movie with video eyewear.

Of the 60 participants enrolled in the present study, there were 31 boys and 29 girls, randomly distributed in treatment group $\mathrm{A}$ and $\mathrm{B}$, with 30 participants each respective group. There were no significant differences between the two groups related to gender $(P=0.78)$. The overall mean age of patients was 5.1 years (range, 4.3-7). The mean ages of the subjects in groups A and B were $4.15 \pm 0.63$ and $6.32 \pm 0.31$ years, respectively [Table 1 ]

In treatment group $\mathrm{A}$, there was a statistically significant difference $(P<0.05)$ observed in pulse rate between the treatment session I and II. Although

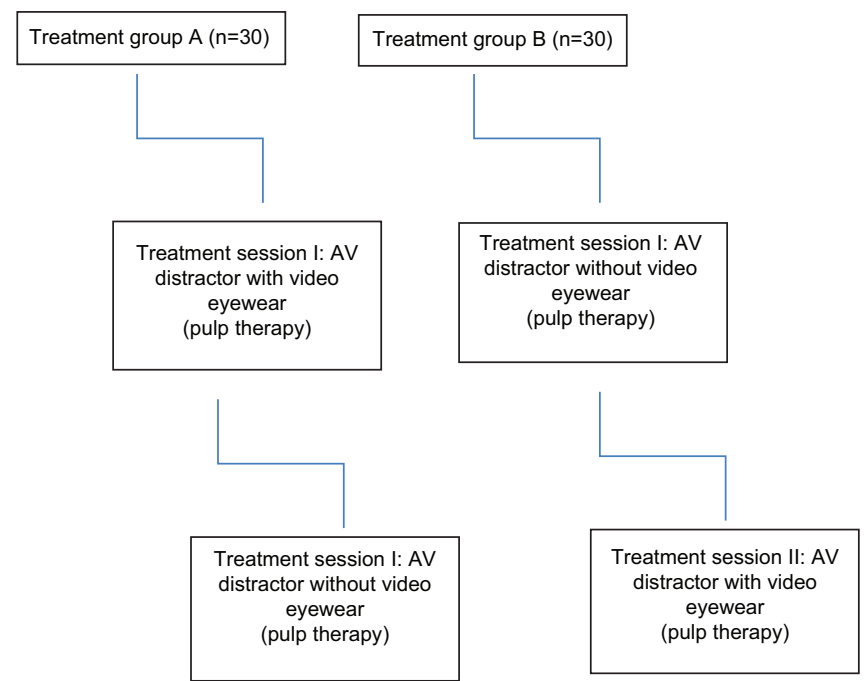

Figure 1: Patient flow through the research study for group B, there observed some positive change that is, decrease in pulse rate between the session I and II, but when compared, the difference does not reach statistical significance $(P=0.09)$. Observations from Table 2 shows that there was no statistically significant difference in oxygen saturation levels between the two sessions in either of the two groups.

Table 3 summarizes the mean change in anxiety from preoperative treatment session I to preoperative treatment session II for both the groups for the MCDAS (f). The mean change in anxiety scores

\begin{tabular}{|c|c|c|c|c|}
\hline \multirow[t]{2}{*}{ Treatment groups } & \multicolumn{2}{|c|}{ Gender } & \multicolumn{2}{|c|}{ Age (years) } \\
\hline & Male & Female & $4-5$ & $6-7$ \\
\hline Treatment group A & 14 & 16 & 16 & 14 \\
\hline Treatment group B & 17 & 13 & 15 & 15 \\
\hline
\end{tabular}

\begin{tabular}{|c|c|c|c|c|}
\hline & \multicolumn{2}{|c|}{$\begin{array}{l}\text { Change in } \\
\text { pulse oximetry }\end{array}$} & \multicolumn{2}{|c|}{$\begin{array}{l}\text { Change in } \\
\text { heart rate }\end{array}$} \\
\hline & Mean & SD & Mean & SD \\
\hline \multicolumn{5}{|l|}{ Group A } \\
\hline $\begin{array}{l}\text { Treatment session 1: AVD } \\
\text { with video eyewear }\end{array}$ & 2.13 & 0.52 & 2.28 & 1.24 \\
\hline $\begin{array}{l}\text { Treatment session 2: AVD } \\
\text { without video eyewear }\end{array}$ & 3.68 & 1.65 & 6.02 & 2.06 \\
\hline$P^{*}$ & 0.41 & & $0.05^{*}$ & \\
\hline \multicolumn{5}{|l|}{ Group B } \\
\hline $\begin{array}{l}\text { Treatment session 1: AVD } \\
\text { without video eyewear }\end{array}$ & 3.54 & 0.58 & 5.67 & 1.06 \\
\hline $\begin{array}{l}\text { Treatment session 2: AVD } \\
\text { with video eyewear }\end{array}$ & 2.51 & 1.08 & 3.12 & 1.01 \\
\hline$P^{*}$ & 0.38 & & 0.09 & \\
\hline
\end{tabular}

\begin{tabular}{|c|c|c|c|}
\hline \multirow{2}{*}{$\begin{array}{l}\text { Treatment groups } \\
\text { Group A }\end{array}$} & \multicolumn{2}{|c|}{ Outcome } & \multirow[t]{2}{*}{$P^{*}$} \\
\hline & $\begin{array}{l}\text { Treatment } \\
\text { session 1: } \\
\text { AVD with } \\
\text { video eyewear }\end{array}$ & $\begin{array}{c}\text { Treatment } \\
\text { session 2: } \\
\text { AVD without } \\
\text { video eyewear }\end{array}$ & \\
\hline $\begin{array}{l}\text { Preoperative MCDAS (f) score } \\
\text { Mean (SD) }\end{array}$ & $15.19(1.02)$ & $7.87(2.06)$ & $0.03^{\star}$ \\
\hline Group B & $\begin{array}{l}\text { Treatment } \\
\text { session 1: } \\
\text { AVD without } \\
\text { video eyewear }\end{array}$ & $\begin{array}{l}\text { Treatment } \\
\text { session 2: } \\
\text { AVD with } \\
\text { video eyewear }\end{array}$ & \\
\hline $\begin{array}{l}\text { Preoperative MCDAS (f) score } \\
\text { Mean (SD) }\end{array}$ & $14.86(1.09)$ & $11.51(2.10)$ & 0.52 \\
\hline
\end{tabular}


observed for group A between two treatment sessions was significant $(P>0.03)$. However, there found no significant change observed in the group who had their first treatment session with AVD without video eyewear.

In group A, the mean faces scale pain scores show an increase, though not significant, between first treatment session when children use video eyewear compared to the second session when they watch the movie without using video eyewear. The difference between the two operative mean pain score was considered different $(P=0.04)$ in group B as the self-reported mean pain score decreases dramatically during treatment session II with video eyewear [Table 4].

\section{DISCUSSION}

Behavioral and physiological findings suggest that the three most feared or anxiety-producing stimuli in the dental operatory are the injection of local anesthesia, application of rubber dam, and initiation of tooth preparation with the high speed handpiece. ${ }^{[15-18]}$

Stimuli found in every dental operatory such as natural fears of bright lights, loud noises, sudden movements, and strange environments are easily aroused in and produce the most overt expressions of anxiety. ${ }^{[3]}$ According to the published guidelines for the clinical management of children by the American Academy of Pediatric Dentistry, ${ }^{[19]}$ distraction, diverting patient's attention from perceived unpleasant procedure to decrease the likelihood of unpleasantness perception and/or threshold, indicated for any pediatric patient of any age. In our study, a statistically significant difference was observed between the two treatment sessions for group B who had their first treatment session without video eyewear and AVD distraction

\begin{tabular}{|c|c|c|c|}
\hline \multirow{2}{*}{$\begin{array}{l}\text { Treatment groups } \\
\text { Group A }\end{array}$} & \multicolumn{3}{|c|}{ Outcome } \\
\hline & $\begin{array}{l}\text { Treatment } \\
\text { session 1: } \\
\text { AVD with } \\
\text { video eyewear }\end{array}$ & $\begin{array}{l}\text { Treatment } \\
\text { session } 2: \\
\text { AVD without } \\
\text { video eyewear }\end{array}$ & $P^{*}$ \\
\hline $\begin{array}{l}\text { WB faces pain rating score } \\
\text { Mean (SD) }\end{array}$ & $1.59(0.56)$ & $2.12(0.72)$ & 0.29 \\
\hline Group B & $\begin{array}{c}\text { Treatment } \\
\text { session 1: } \\
\text { AVD without } \\
\text { video eyewear }\end{array}$ & $\begin{array}{l}\text { Treatment } \\
\text { session 2: } \\
\text { AVD with } \\
\text { video eyewear }\end{array}$ & \\
\hline $\begin{array}{l}\text { WB faces pain rating score } \\
\text { Mean (SD) }\end{array}$ & $4.01(0.60)$ & $2.16(0.73)$ & $0.04^{*}$ \\
\hline
\end{tabular}

with video eye wear in a subsequent session. Mean change in pain severity decreased from $4.01 \pm 0.60$ to $2.16 \pm 0.73 ; P=0.04$.

The video eyewear may be better distraction than watching video projected on the screen as due to the occlusive eyewear that project the images right in front of the eyes of the user and, blocking out real world's visual and auditory stimuli. The child's attention will be more or less "diverted" from the real world, leaving them less attentive to the real world activities. To be effective, this cognitive behavioral intervention that diverts attention from a stressful stimulus and focuses it onto a more pleasant one, ${ }^{[20-24]}$ must be age appropriate and it must be appealing to the recipient. ${ }^{[25,26]}$ Animated cartoons on pleasant topics have been demonstrated to be an effective focus interesting most children and seem a safe and easy to administer the stimulus for distraction therapy. ${ }^{[20,22]}$

During a dental procedure, effective pain control in children is important to achieve comfort, cooperation, and compliance. ${ }^{[27,28]}$ Several methods have been introduced, which include the application of topical anesthetic before injection, use of fine (smaller gauges extra short) needles, and slow delivery of the anesthetic solution to reduce the pain during local anesthesia. ${ }^{[11,28,29]}$ In our study, in contrast to the intraligamentary injection using conventional dental syringe which induces (1200 psi) of pressure, we used CDS (Wand, Milestone Scientific, Inc., Deerfield, IL) enabling slow-paced delivery of local anesthetic, in small volume under a controlled low pressure of (165 pound/square inch, psi). In addition, employing CDS-intrasulcular (IS) system enables operator to control the disadvantages associated with an inferior alveolar block such as pain that affects child's behavior and avoids postoperative self-inflicted injuries (tongue or lip biting) owing to its localized effect and bilateral procedures can be done during one session. ${ }^{[30-34]}$

According to some studies, ${ }^{[35-37]}$ CDS-IS anesthesia is less effective for pulp therapies. In addition, some other studies, ${ }^{[38,39]}$ also noticed that routinely used procedure for anesthetizing the maxillary second primary molars had low success. This could be due to the fact that most of these teeth were showing signs of inflammation which could lead to the possibility of reduced efficacy of the anesthetic solution. According to Ashkenazi et al., ${ }^{[34]}$ dense and thick nature of zygomatic bone, as well as deep position of the apex of maxillary second primary molars, could hampers the effectiveness of anesthesia. For the 
very reason, in addition to intraligament anesthesia operator we also give intrapulpal anesthesia to have completely effective anesthesia during all the sessions of pulp therapy for both the groups. Furthermore, in agreement with other studies, for the operator, it is difficult to measure the precise amount of local anesthetic and the most reported oral complaints was of bitter taste of the anesthesia solution that had leaked into children's mouth. ${ }^{[34]}$

In the present study, the mean pain scores, although not significant for group A, shows a slight increase, between first treatment session when children uses video eyewear compared to the second session when they watch the movie without using video eyewear. This slight difference could be because of the absence of video eyewear to completely block the visual field, which triggers anxiety, which children relate as pain and not because of the ineffective anesthesia.

The cooperation of the child can influence the decision to retain primary teeth by treating pulpal conditions but the use of audiovisual distraction with video eyewear and use of CDS-IS system for anesthetic delivery was demonstrated to be effective in improving children's cooperation. In addition to this, there is a reduction in self-reported pain during pulp therapy procedure.

This combination modality using audiovisual distraction with video eyewear along with CDS-IS system for anesthetic delivery during pulp therapy, to reduce the child dental anxiety, seems to be more effective than routine psychological interventions. Moreover, is, therefore, highly recommended as an effective behavior management technique for the long invasive procedures of pulp therapy in young children.

\section{Financial support and sponsorship}

Nil.

\section{Conflicts of interest}

There are no conflicts of interest.

\section{REFERENCES}

1. Arntz A, van Eck M, Heijmans M. Predictions of dental pain: The fear of any expected evil, is worse than the evil itself. Behav Res Ther 1990;28:29-41.

2. Ince B, Ercan E, Dalli M, Dulgergil CT, Zorba YO, Colak H. Incidence of postoperative pain after single- and multi-visit endodontic treatment in teeth with vital and non-vital pulp. Eur J Dent 2009;3:273-9.

3. Pinkham JR, Casamassimo PS, McTigue DJ, Fields HW Jr, Nowak AJ. Infancy Through Adolescence, Pediatric Dentistry. $4^{\text {th }}$ ed. Philadelphia, Pa: Elsevier Saunders; 2005.
4. Allen KD, Stanley RT, McPherson K. Evaluation of behavior management technology dissemination in pediatric dentistry. Pediatr Dent 1990;12:79-82.

5. Mahesh R, Prasad V, Menon PA. A case of accidental aspiration of an endodontic instrument by a child treated under conscious sedation. Eur J Dent 2013;7:225-8.

6. Prabhakar AR, Marwah N, Raju OS. A comparison between audio and audiovisual distraction techniques in managing anxious pediatric dental patients. J Indian Soc Pedod Prev Dent 2007;25:177-82.

7. Wismeijer AA, Vingerhoets AJ. The use of virtual reality and audiovisual eyeglass systems as adjunct analgesic techniques: A review of the literature. Ann Behav Med 2005;30:268-78.

8. Sinha M, Christopher NC, Fenn R, Reeves L. Evaluation of nonpharmacologic methods of pain and anxiety management for laceration repair in the pediatric emergency department. Pediatrics 2006;117:1162-8.

9. Dahlquist LM, Weiss KE, Clendaniel LD, Law EF, Ackerman CS, McKenna KD. Effects of videogame distraction using a virtual reality type head-mounted display helmet on cold pressor pain in children. J Pediatr Psychol 2009;34:574-84.

10. Sullivan C, Schneider PE, Musselman RJ, Dummett CO Jr, Gardiner D. The effect of virtual reality during dental treatment on child anxiety and behavior. ASDC J Dent Child 2000;67:193-6, 160-1.

11. Allen KD, Kotil D, Larzelere RE, Hutfless S, Beiraghi S. Comparison of a computerized anesthesia device with a traditional syringe in preschool children. Pediatr Dent 2002;24:315-20.

12. Gibson RS, Allen K, Hutfless S, Beiraghi S. The wand vs. traditional injection: A comparison of pain related behaviors. Pediatr Dent 2000;22:458-62

13. Howard KE, Freeman R. Reliability and validity of a faces version of the Modified Child Dental Anxiety Scale. Int J Paediatr Dent 2007;17:281-8.

14. Hockenberry MJ, Wilson D, Winkelstein ML. Wong's Essentials of Pediatric Nursing. $7^{\text {th }}$ ed. St. Louis: Mosby/Elsevier; 2005. p. 1259.

15. Badalaty MM, Houpt MI, Koenigsberg SR, Maxwell KC, DesJardins PJ A comparison of chloral hydrate and diazepam sedation in young children. Pediatr Dent 1990;12:33-7.

16. Currie WR, Biery KA, Campbell RL, Mourino AP. Narcotic sedation: An evaluation of cardiopulmonary parameters and behavior modification in pediatric dental patients. J Pedod 1988;12:230-49.

17. Doring KR. Evaluation of an alphaprodine-hydroxyzine combination as a sedative agent in the treatment of the pediatric dental patient. J Am Dent Assoc 1985;111:567-76.

18. Houpt MI, Weiss NJ, Koenigsberg SR, Desjardins PJ. Comparison of chloral hydrate with and without promethazine in the sedation of young children. Pediatr Dent 1985;7:41-6.

19. American Academy of Pediatric Dentistry. Elective use of minimal, moderate and deep sedation and general anesthesia in pediatric dental patients. Pediatric Dent 2004;24:90-8.

20. Bellieni CV, Cordelli DM, Raffaelli M, Ricci B, Morgese G, Buonocore G. Analgesic effect of watching TV during venipuncture. Arch Dis Child 2006;91:1015-7.

21. Hoffman HG, Doctor JN, Patterson DR, Carrougher GJ, Furness TA $3^{\text {rd }}$. Virtual reality as an adjunctive pain control during burn wound care in adolescent patients. Pain 2000;85:305-9.

22. Cassidy KL, Reid GJ, McGrath PJ, Finley GA, Smith DJ, Morley C, et al. Watch needle, watch TV: Audiovisual distraction in preschool immunization. Pain Med 2002;3:108-18.

23. Sparks L. Taking the "ouch" out of injections for children. Using distraction to decrease pain. MCN Am J Matern Child Nurs 2001;26:72-8.

24. Dowling JS. Humor: A coping strategy for pediatric patients. Pediatr Nurs 2002;28:123-31

25. O'Donnell JJ, Maurice SC, Beattie TF. Emergency analgesia in the paediatric population. Part III non-pharmacological measures of pain relief and anxiolysis. Emerg Med J 2002;19:195-7.

26. Rusy LM, Weisman SJ. Complementary therapies for acute pediatric pain management. Pediatr Clin North Am 2000;47:589-99.

27. Berggren U, Meynert G. Dental fear and avoidance: Causes, symptoms, and consequences. J Am Dent Assoc 1984;109:247-51.

28. Jones CM, Heidmann J, Gerrish AC. Children's ratings of dental injection and treatment pain, and the influence of the time taken to administer the injection. Int J Paediatr Dent 1995;5:81-5.

29. Hochman M, Chiarello D, Hochman CB, Lopatkin R, Pergola S. 
Computerized local anesthetic delivery vs. traditional syringe technique. Subjective pain response. N Y State Dent J 1997;63:24-9.

30. Schleder JR, Reader A, Beck M, Meyers WJ. The periodontal ligament injection: A comparison of $2 \%$ lidocaine, 3\% mepivacaine, and $1: 100,000$ epinephrine to $2 \%$ lidocaine with $1: 100,000$ epinephrine in human mandibular premolars. J Endod 1988;14:397-404.

31. Oztas N, Ulusu T, Bodur H, Dogan C. The wand in pulp therapy: An alternative to inferior alveolar nerve block. Quintessence Int 2005;36:559-64.

32. Malamed SF. Sedation: A Guide to Patient Management. $4^{\text {th }}$ ed. St. Louis, MO: CV Mosby Co.; 2003. p. 337.

33. Ran D, Peretz B. Assessing the pain reaction of children receiving periodontal ligament anesthesia using a computerized device (Wand). J Clin Pediatr Dent 2003;27:247-50.

34. Ashkenazi M, Blumer S, Eli I. Effectiveness of computerized delivery of intrasulcular anesthetic in primary molars. J Am Dent Assoc 2005;136:1418-25.

35. Nakai Y, Milgrom P, Mancl L, Coldwell SE, Domoto PK, Ramsay DS. Effectiveness of local anesthesia in pediatric dental practice. J Am Dent Assoc 2000;131:1699-705.

36. Oulis CJ, Vadiakas GP, Vasilopoulou A. The effectiveness of mandibular infiltration compared to mandibular block anesthesia in treating primary molars in children. Pediatr Dent 1996;18:301-5.

37. Sharaf AA. Evaluation of mandibular infiltration versus block anesthesia in pediatric dentistry. ASDC J Dent Child 1997;64:276-81.

38. Ralph E, McDonland RE, Avery DR. Local anesthe $\neg$ sia for the child and adolescent. In: McDonland RE, Avery DR, editors. Dentistry for the Child and Adolescent. $7^{\text {th }}$ ed. St. Louis, MO: CV Mosby Co.; 1985. p. 288-90.

39. Wright GZ, Starkey PE, Gardiner DE. Managing Children's Behavior in the Dental Office. St. Louis, MO: CV Mosby Co.; 1983. p. 132-3.

\begin{tabular}{|l|l|}
\hline \multicolumn{3}{|c|}{ Access this article online } \\
\hline Quick Response Code: & \\
\hline
\end{tabular}

